\title{
The Relationship Between Parental and Teachers' Autonomy Support, Enjoyment, Self-Efficacy, Academic Effort and P-E class Flow by Middles School Students Participating in P.E Classes
}

\author{
Hunhyuk Choi ${ }^{1}$ and Seongkwan $\mathrm{Cho}^{2 *}$ \\ ${ }^{1}$ Department of Physical Education, Kangwon National University, Chuncheon, Korea \\ ${ }^{2}$ Department of Health Sciences, Texas A\&M International University, Laredo, TX, USA
}

\begin{abstract}
[Purpose] The aim of this study was to examine how middles school students in physical education class perceived relations between parental and teacher's autonomy support, enjoyment, self-efficacy, academic effort, and P.E class flow. This study also investigate the mediating effects of enjoyment, self-efficacy, and academic effort on the relations between parental autonomy support and $\mathrm{P} \cdot \mathrm{E}$ class flow and between teacher's autonomy support and P.E class flow. [Methods] For this study, 323 middle school students completed surveys to measure their perceptions of parental and teacher's autonomy support, enjoyment, self-efficacy, academic effort, and P-E class flow. SPSS 24.0 was used to calculate descriptive statistics, reliability, and correlations. Amos 22.0 was utilized for confirmatory factor analysis, convergent validity, discriminant validity, and structural equation modeling. Additionally, 2000 bootstrap samples were requested for the mediation effect analysis. [Results] First, parental autonomy support was positively predictive of enjoyment and self-efficacy. Second, teacher's autonomy support positively influenced enjoyment and self-efficacy. Third, enjoyment and self-efficacy positively affected academic effort. Forth, academic effort was positively related to P E class flow. Fifth, there were partial mediating effects of enjoyment, self-efficacy, and academic effort on the relationship between parental autonomy support and P E E class flow. Lastly, there were partial mediating effects of enjoyment, self-efficacy, and academic effort on the relationship between teacher's autonomy support and $\mathrm{P} \cdot \mathrm{E}$ class flow. [Conclusions] The study found that teachers' autonomy support was stronger predictive of student's $\mathrm{P} \cdot \mathrm{E}$ class flow in physical education class than parent's autonomy support was. The finding is meaningful in that it is worth providing and utilizing practical knowledge from an educational perspective.
\end{abstract}

Key words: parent and teacher autonomy support, enjoyment, self-efficacy, academic effort, $\mathrm{P} \cdot \mathrm{E}$ class flow

\section{서 론}

\section{1. 연구의 필요성}

논문 투고일 : 2021.06.02.

논문 수정일 : 2021.06.16.

게재 확정일 : 2021.06.30.

* 교신저자 : 조승관(scho@tamiu.edu)
학생선수와 운동선수들의 인권과 학교폭력에 대한 구조 적 문제는 사회적 문제로 대두되고 있다. 최근 운동선수나 
연예인 등 많은 유명인들이 과거 학교 폭력에 대한 사실이 드 러나면서 사회적으로 큰 이슈가 되었다. 이러한 문제는 단순 히 학생들 간의 문제가 아닌 사회 구조나차별과 관련되기 때 문에 예방과 근절을 위해 국가, 사회, 학교, 그리고 가정 등 우리 모두의 노력이 절대적으로 필요하다. 따라서 이러한 문 제를 예방 및 근절하기 위해서는 근본적으로 가정과 학교생 활에서 많은 관심과 노력을 기울여야 할 것으로 생각한다.

학생 발달에 있어 중요한 역할을 하는 사회적 환경 중 대 표적인 존재는 부모와 교사(Van der Kaap-Deeder et al., 2017)로 그들이 지지하는 자율성은 학습자 및 자녀에게 다 양한 선택의 기회를 제공하고, 이들이 추구하는 가치와 흥미 를 탐색할 수 있도록 도움을 제공하며, 무엇보다 이들의 관 점에서 이해하려고 노력한다(Soenens \& Vansteenkiste, 2005; Vansteenkiste, Lens, \& Deci, 2006). 특히, 청소 년기에는 신체적, 인지적으로 급격한 발달 및 변화를 보이는 데 이때, 학습자는 자신의 의사결정권을 보다 더 많이 갖기를 기대하기(Chen, 2010) 때문에 부모와 교사의 양육방식이 나 교수법은 매우 중요하다(Reeve \& Jang, 2006). 반면, 부 모와 교사의 심리적 통제가 높으면 학습자의 자율성 동기가 낮아 감정조절, 행동 및 학습에 대한 문제 특히, 학업 성취도 를 부정적으로 예측한다(Aunola \& Nurmi, 2004). 이는 결 과적으로 부모와 교사의 인정, 격려가 자녀와 학습자 간의 긍 정적 상호작용으로 이어져 학습자의 학교생활이나 수업에서 의 노력과 몰입, 심리적 안녕감뿐만 아니라 미래지향적 삶의 목표설계 등에 큰 영향을 미칠 것이다. Ryan \& $\operatorname{Deci}(2000$, 2009)에 의하면, 자기결정성 동기가 더 높은 학생은 자기결 정성 동기가 적은 학생보다 더 많은 노력과 인내(끈기), 즐거 움을 보이며 무엇보다 체육수업 환경에서 더 많은 자기결정 성을 지닌 학생들은 신체 활동에 참여하려는 의지가 더 강하 고, 미래에 선택적 체육교육에 참여할 가능성이 높고, 여가 시간에서도 상당히 활동적임을 보고하였다(Hagger, Chatzisarantis, Culverhouse, \& Biddle, 2003).

한편, Scanlan \& Simons(1992)은 즐거움(enjoyment) 의 구성개념을 기쁨(pleasure), 좋아함(liking), 그리고 재 미(fun)와 같은 일반화된 감정을 반영하는 스포츠 경험에 대한 긍정적인 정서 반응으로 정의하였다. Deci, \& Ryan(1980)은 즐거움(enjoyment)과 내재적 동기의 구성 을 다소 상호 교환적으로 사용하지만, Scanlan \& Lewthwaite(1986)는 이 두 구성개념을 명확하게 구별할 필요가 있음을 주장하면서 즐거움을 다양한 자원(sources)
을 가진 더 광범위하고 포괄적인 구성개념으로 보았다. 즐 거움에 대한 중요성은 스포츠 동기와 관련하여 청소년 및 엘 리트 운동선수들의 참여동기 및 중도 포기와 관련된 연구에 서 확인되며 특히, Brusted(1993)는 청소년 선수들이 스포 츠에 참여하는 중요한 이유로 "즐거움"을 제시하였다. Brusted(1993)뿐만 아니라 Gould(1987)는 스포츠를 중 도에 포기하는 주요원인을 즐거움 부족으로 보고, 부모의 압박이 낮을수록 농구선수의 즐거움은 더 크다고 언급하였 다. 즐거움은 청소년들이 신체적으로 활동하도록 동기를 부 여하는 중요한 매개 요인이 될 수 있다(Dishman et al., 2005). 체육수업에서 본질적으로 높은 수준의 기술을 바탕 으로 다양한 수업과제에 참여하는 학습자는 더 즐겁고, 흥 미로울 것이다. Fisher \& Noble(2004)은 과제에 대한 관 심은 노력을 긍정적으로 예측한다는 사실을 보고였다.

국내에서도 즐거움이 학생들에 긍정적인 영향을 미친다 는 연구(Kim, Kim, Won, 2015; Park, Lee, 2019; Park, Cho, 2020)들 또한 즐거움이 커질수록 더 열심히 노력하 고, 수업에 몰입하는 것으로 보고되었다. 체육수업에서 이 러한 과정은 긍정적 수업 참여로 귀결될 것이다. 따라서 교 사는 학습자들이 체육수업에 즐겁게 참여할 수 있는 환경을 제공함으로써 학습자들의 학습노력을 이끌어 낼 수 있겠지 만 만약, 수업 내용이 흥미를 이끌어 내지 못하거나 또는 학 습자 스스로 가치가 없다는 인식을 경험하게 하는 등의 내재 적 동기가 제공되지 못한다면 학습자들은 수업에 형식적으 로 참여하게 되고 이에 대한 빈도가 높아지면 학습에서의 무 동기를 경험할 수도 있게 될 것이다.

사회적인지 이론(social cognitive theory; SCT, Bandura, 1997)은 기대 가치와 사회적 학습이론(Bandura, 1977; Rotter, 1960)에서 파생되었으며 개인, 환경 및 행동 요인이 서로 상호작용하는 결정요인으로 작용한다. SCT에 포함된 주요 인지과정은 자기효능감, 결과 기대 가치, 목표설 정 및 만족으로 이는 신체활동에 직접적인 영향을 미친다. 따 라서 체육수업에 참여하는 학습자는 신체 활동에 대해 긍정 적인 결과에 대한 기대치를 갖고 도전적인 목표를 선택하여 과제를 달성할 수 있는 능력이 있다고 믿는다면 아마도 그들 은 최적의 동기를 갖게 될 것이다. 자기효능감(Bandura, 1997)은 특정 과제를 성공적으로 해결할 할 수 있다는 자신 의 능력에 대한 믿음이나 기대감이다. 이에 Bandura(1997) 는 행동에 참여할 충분한 동기가 주어지면 그 행동이 시작될 것인지, 얼마나 많이 그리고 오랫동안 노력할 것인지를 결정 
하는 것은 개인의 신념이라고 언급하였다.

Wolters \& Rosenthal(2000)은 과제수행을 위한 학습자 들의 노력은 믿음과 태도에서 유발되며, 개인의 능력이 선천 적인 것과 상관없이 노력에 의해 개선될 수 있다고 판단할 때, 노력과 지속행동은 달라진다고 하였다. Gao \& Harrison (2008)은 학습자들의 자기효능감은 내적동기(노력, 지속성)와 관계가 있음을 증명하였다. Boiche et al.(2008)에 의하면 자 기효능은 높은 수준의 노력과 긍정적으로 관련이 있기 때문에 자신의 능력에 자신감을 보이는 학습자는 많은 노력과 높은 만 족감(Jackson \& Beauchamp, 2010)을 갖는다고 하였다. 스 포츠 분야에서도 자기효능감과 관련된 연구는 수행되었는데 Hutchinson et al.(2008)은 자기효능감에 대한 믿음은 과제 에 투여하는 노력을 포함한 바람직한 행동의 결과를 가져온다 고 보고하였다. 결과적으로 체육수업에서 학습자들의 자기효 능감에 대한 믿음은 고정적인 개인의 특성이 아닌 과제에 따라 다르게 나타날 수 있는 가변적 성향을 가지고 있기 때문에 수 업시간에 학습하는 과제를 성공적으로 수행했을 경우 자기효 능감은 높아지며, 높은 자기효능감은 학업노력을 비롯한 수업 몰입의 경험을 기대할 수 있다.

몰입의 경험은 일시적이고, 이런 특성으로 인해 복잡하고 측정하기가 어렵다. 더욱이 수업에서의 몰입 경험은 지금 활 동에 전적으로 집중하고 그것을 수행하는 동안 즐거움을 경 험하는 것으로(Chen, 2006; Csikszentmihalyi, 1990) 성 취하고자 하는 학습결과를 위해 학습자가 투자하는 노력의 질로 정의된다(Coates, 2006). Mark(2000)는 몰입이 높은 학습자는 집중, 즐거움, 그리고 노력을 지속하는 경향을 보 이기 때문에 능동적 학습에서 수업몰입을 핵심적 요소로 언 급하였다. Lee(2011)의 연구에서 자기효능감은 수업몰입과 높은 상관관계가 있음을 제시하였다. Schilling(2009)은 수 업시간에 능동적, 자기주도적 관여를 통해 지식을 습득하고, 능력을 숙달하기 위해 자발적 노력과 집중을 수업몰입으로 정의하면서 행동적, 감정적, 인지적 반응과 태도를 포함한 다차원적 개념으로 확장하였다. 행동적 몰입은 학습활동 참 여, 과제 지속, 질문하기 등을 의미하고, 감정적 몰입은 수업 에서의 소속감, 일체감, 학습가치의 내재, 그리고 학습자가 심리적으로 완전히 빠져든 몰입(flow)의 경험 상태를 의미하 며, 아울러 인지적 몰입은 동기와 노력, 인지 및 조절전략을 사용하는 것과 도전적으로 요구된 것을 성취해내는 인지적 노력을 의미한다(Park, Oh, 2016, 재인용). 결과적으로 학 습자들이 체육수업에 대해 즐거움을 느끼고 자기효능감이
높아 도전적인 과제를 선택해서 이를 성공적으로 수행하기 위해 노력을 기울이는 경우에는 내재적 동기 발생으로 인해 수업 몰입에 영향을 미칠 것으로 생각된다.

언급한 내용을 종합해 보면 그동안 다양한 영역에서 수업 몰입에 대한 연구는 꾸준히 보고되어 왔다. 하지만 부모와 교사의 자율성지지와 수업몰입의 관계에서 즐거움, 자기효 능감, 그리고 학습노력의 매개효과를 확인하기 위해 진행된 연구는 상당히 미흡하다. 따라서 실제 학교 현장에서 적용 된 선행연구 및 이론적 자료를 바탕으로 상정된 변인들에 대 한 분석은 향후 체육수업에서 즐거움 및 자기효능감과 학습 노력의 감소를 막고, 나아가 학습자들의 인성 및 학교폭력 에 대한 문제를 근본적으로 예방 및 근절하기 위한 교육자들 의 노력을 이끌어 낼 수 있을 것이다.

이에 본 연구에서는 부모와 교사의 자율성지지와 수업몰 입의 관계를 분석하고, 아울러 부모와 교사의 자율성지지와 수업몰입의 관계에서 즐거움, 자기효능감, 그리고 학습노력 이 어떠한 매개효과가 있는지를 확인하고자 하였다.

\section{2. 연구 가설}

연구의 목적을 규명하기 위해 이론적 근거와 실증적 자료 를 바탕으로 다음과 같은 연구가설을 설정하였다〈Fig. 1〉. 첫째, 부모의 자율성지지는 즐거움과 자기효능감에 영향을 미칠 것이다. 둘째, 교사의 자율성지지는 즐거움과 자기효 능감에 영향을 미칠 것이다. 셋째, 즐거움과 자기효능감은 학업노력에 영향을 미칠 것이다. 넷째, 학업노력은 수업몰 입에 영향을 미칠 것이다. 다섯째, 부모의 자율성지지와 수 업몰입의 관계에서 즐거움, 자기효능감 그리고 학업몰입은 매개효과가 있을 것이다. 마지막으로 교사의 자율성지지와 수업몰입의 관계에서 즐거움, 자기효능감 그리고 학업몰입 은 매개효과가 있을 것이다.

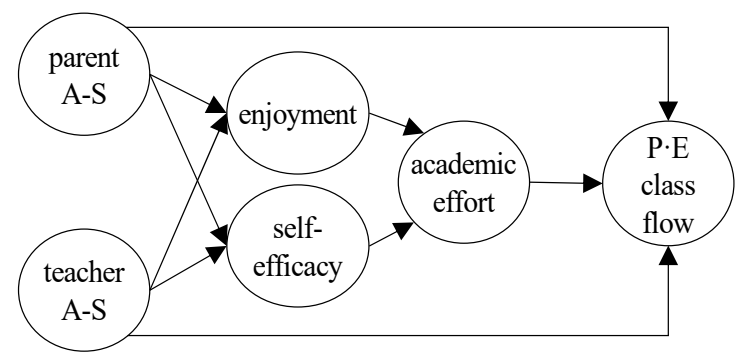

Figure 1. Research model 


\section{연구방법}

\section{1. 연구대상}

본 연구에서는 체육수업에 참여하는 남.여 중학생 323명 을 연구대상자로 선정하였다. 구체적으로 남학생 149명 (46.17\%)과 여학생 174명(53.9\%)이 본 연구에 참여하였 다. 연구 참여자들의 학년은 1 학년 120 명(37.2\%), 2학년 116 명(35.9\%), 3학년 87명(26.9\%)으로 나타났다. 학생들 이 지각하는 운동수준은 상 108 명(33.4\%), 중 166명 (51.4\%), 하 49명(15.2\%)으로 조사되었고, 이들 중 174 명 (53.9\%)이 체육수업에 대해 매우 만족하는 것으로 120 명 (37.2\%)은 만족, 그리고 29명(9\%)은 보통 수준으로 지각하 고 있었다〈Table 1〉.

Table 1. The demographic characteristics of participants

\begin{tabular}{cccc}
\hline \hline & Variable & $\mathrm{N}$ & $\%$ \\
\hline \multirow{2}{*}{ Gender } & Male & 149 & 46.1 \\
\cline { 2 - 4 } & Female & 174 & 53.9 \\
\hline \multirow{2}{*}{ Grade } & First Year & 120 & 37.2 \\
Level & Second Year & 116 & 35.9 \\
& Third Year & 89 & 26.9 \\
\hline \multirow{2}{*}{ Exercise } & High & 108 & 33.4 \\
Level & Middle & 166 & 51.4 \\
& Low & 49 & 15.2 \\
\hline \multirow{2}{*}{ Class } & Very Satisfied & 174 & 53.9 \\
\cline { 2 - 4 } Satisfaction & Satisfied & 120 & 37.2 \\
\cline { 2 - 4 } & Usually & 29 & 9.0 \\
\hline \hline
\end{tabular}

\section{2. 측정도구}

본 연구에서의 측정도구는 모두 Likert 5점 척도(매우 아니다= 1점, 매우 그렇다= 5점)로 구성하였고, 자기보고 식으로 측정하였다. 아울러 Cronbach's $\alpha$ 를 통해 측정도 구의 신뢰도를 확인하였다.

먼저 부모의 자율성지지는 척도는 Soenens, Vansteenkiste et al.(2007)이 개발하고 Lee(2013)가 타 당화한 척도를 사용하였다. 원척도는 '독립성 증진
(Promotion of Independence)'과 '의지기능증진 (Promotion of Volitional Functioning)'의 2요인으로 구성되어 있으나 본 연에서는 자기결정성이론의 자율성 개 념이 반영된 의지기능증진 요인을 활용하였다. 이 요인의 경우 자녀의 의견에 동조적이면서 통제 및 권위적 행동을 하 지 않고, 자녀에게 선택의 기회를 제공하면서, 가치관이나 흥미를 탐색하는데 도움을 제공한다는 측면이 반영되어 있 다는 점을 고려하였다. 본 연구에서의 신뢰도 계수는 .940 으로 나타났다.

중학생들이 지각한 교사의 자율성지지는 자기결정성 이 론에 근거하여 Cheon et al.(2017)이 개발하고, Lee, Cheon, Kim, Song(2017)이 타당화한 척도를 사용하였 다. 이 척도는 4 요인으로 구성되어 있으나 본 연구에서는 자기결정성이론에 근거하여 개발된 측정도구라는 점을 반 영하여 교사의 자율성지지 요인을 활용하였다. 이 요인의 경우 교사가 자율성을 지지하는 방식의 소통을 학습자의 입장, 활동의 당위성 제시, 언어적 표현 활용, 스스로 학습 활동을 할 수 있는 시간제공, 자율성을 자아내고 길러내는 것으로 제시되어 있다는 점을 고려하였다. 교사의 자율성 지지는 6문항-체육선생님은 나의 의견이나 생각을 받아들 이고 귀담아 들어준다)으로 구성되어 있으며, 본 연구에서 의 신뢰계수는 .907 로 나타났다.

즐거움과 자기효능감 척도는 $\mathrm{Kim}, \mathrm{Kim}(2008)$ 이 개발 하고, Yu, Sohn(2013)이 활용한 척도를 사용하였다. 본 연에서는 각각 4문항-(좋아하는 교과목이 있어 학교생활이 재미있다, 학교에서 내게 주어진는 과제나 일을 정해진 시 간에 잘 마치는 내가 만족스럽다)으로 구성하였다. 본 연구 에서의 신뢰도 계수는 즐거움 .864, 자기효능감 .883으로 나타났다.

학업노력은 Shin, Jin(2013)이 활용한 문항을 사용하였 다. 원척도는 학업 상황에서 사용한 것이므로 중학교 체육 선생님 그리고 스포츠 교육학 전공 교수와 논의를 거쳐 측정 문항을 체육수업 상황으로 수정해도 내용적으로 타당한지 를 검토하였다. 예컨대, '나는 공부를 가능한 한 열심히 하려 고 한다' 는 문항은 '나는 체육수업에서 운동을 가능한 한 열 심히 하려고 한다. 로 수정하였다. 본 연구서에서는 학업 노 력 4문항을 활용하였고, 신뢰도 계수는 .895로 나타났다.

마지막으로 수업몰입은 $\mathrm{He}(2009)$ 가 사용한 몰입 척도 를 You(2011)이 타당화한 척도를 활용하였다. 원척도는 인지적 몰입 9문항, 감성적 몰입 5문항, 행동적 몰입 6문항 
으로 구성되었다. 원척도는 학업 상황에서 사용한 것이므 로 중학교 체육선생님 그리고 스포츠 교육학 전공 교수와 논의를 거쳐 측정문항을 체육수업 상황으로 수정해도 내용 적으로 타당한지를 검토하였다. 예컨대, 인지적 몰입 문항 의 '정기적으로 공부를 한다'.는 문항은 '나는 정기적으로 운동을 한다'. 로 수정하였고, 또한 감성적 몰입 문항의 '배
운 내용을 실제 생활에 적용해 본다' 는 문항은 '나는 체육 수업시간에 배운 내용을 실생활에 적용해 본다' 그리고 행 동적 몰입 문항의 '다른 동료학생들을 도와준다' 는 문항은 '나는 체육시간에 다른 친구들을 도와준다' . 로 수정하였 다. 본 연구에서의 신뢰도 계수는 인지적 몰입 .846, 감성 적 몰입 .893, 그리고 행동적 몰입 .871로 나타났다.

Table 2. Factor loading $(\lambda)$, SRW, CR, and AVE values of measurement model

\begin{tabular}{|c|c|c|c|c|c|c|c|c|}
\hline Variable & Path & Item & Estimate & $\beta$ & $\mathrm{t}$ & C.R & AVE & Cronbach's o \\
\hline \multirow{8}{*}{$\begin{array}{c}\text { Parent } \\
\text { A-S }\end{array}$} & $\rightarrow$ & PAS1 & 1.000 & 0.719 & - & \multirow{8}{*}{.921} & \multirow{8}{*}{.593} & \multirow{8}{*}{.940} \\
\hline & $\rightarrow$ & PAS2 & 1.136 & 0.762 & $13.287 * * *$ & & & \\
\hline & $\rightarrow$ & PAS3 & 1.109 & 0.765 & $13.347 * * *$ & & & \\
\hline & $\rightarrow$ & PAS4 & 1.154 & 0.748 & $13.033^{* * *}$ & & & \\
\hline & $\rightarrow$ & PAS5 & 1.371 & 0.812 & $14.163 * * *$ & & & \\
\hline & $\rightarrow$ & PAS6 & 1.143 & 0.719 & $12.523^{* * *}$ & & & \\
\hline & $\rightarrow$ & PAS7 & 1.200 & 0.801 & $13.969 * * *$ & & & \\
\hline & $\rightarrow$ & PAS8 & 1.278 & 0.826 & $14.423^{* * *}$ & & & \\
\hline \multicolumn{9}{|c|}{$\chi^{2}=156.448 \mathrm{df}=20, \mathrm{p}<.000, \mathrm{TLI}=.907, \mathrm{CFI}=.937, \mathrm{RMSEA}=.080, \mathrm{SRMR}=.044$} \\
\hline \multirow{6}{*}{$\begin{array}{c}\text { Teacher } \\
\text { A-S }\end{array}$} & $\rightarrow$ & TAS1 & 1.032 & 0.793 & $15.036^{* * *}$ & \multirow{6}{*}{.909} & \multirow{6}{*}{.626} & \multirow{6}{*}{.907} \\
\hline & $\rightarrow$ & TAS2 & .972 & 0.809 & $15.389 * * *$ & & & \\
\hline & $\rightarrow$ & TAS3 & 1.168 & 0.764 & $14.388^{* * *}$ & & & \\
\hline & $\rightarrow$ & TAS4 & 1.207 & 0.825 & $16.753^{* * *}$ & & & \\
\hline & $\rightarrow$ & TAS5 & 1.082 & 0.779 & $14.723^{* * *}$ & & & \\
\hline & $\rightarrow$ & TAS6 & 1.000 & 0.774 & - & & & \\
\hline \multicolumn{9}{|c|}{$\chi^{2}=68.594 \mathrm{df}=9, \mathrm{p}<.000, \mathrm{TLI}=.960, \mathrm{CFI}=.979, \mathrm{RMSEA}=.080, \mathrm{SRMR}=.025$} \\
\hline \multirow{4}{*}{ Enjoyment } & $\rightarrow$ & enjoy1 & 1.000 & 0.849 & - & \multirow{4}{*}{.870} & \multirow{4}{*}{.629} & \multirow{4}{*}{864} \\
\hline & $\rightarrow$ & enjoy2 & 1.009 & 0.870 & $18.782 * * *$ & & & \\
\hline & $\rightarrow$ & enjoy3 & 1.010 & 0.799 & $16.722 * * *$ & & & \\
\hline & $\rightarrow$ & enjoy4 & .822 & 0.631 & $12.139^{* * *}$ & & & \\
\hline \multirow{4}{*}{ Self-Efficacy } & $\rightarrow$ & SE1 & 1.113 & 0.825 & $14.858^{* * *}$ & \multirow{4}{*}{.884} & \multirow{4}{*}{.657} & \multirow{4}{*}{.883} \\
\hline & $\rightarrow$ & SE2 & 1.113 & 0.835 & $15.063^{* * *}$ & & & \\
\hline & $\rightarrow$ & SE3 & 1.112 & 0.829 & $14.945^{* * *}$ & & & \\
\hline & $\rightarrow$ & SE4 & 1.000 & 0.749 & - & & & \\
\hline \multicolumn{9}{|c|}{$\chi^{2}=54.332 \mathrm{df}=19, \mathrm{p}<.000, \mathrm{TLI}=.966, \mathrm{CFI}=.977, \mathrm{RMSEA}=.076, \mathrm{SRMR}=.033$} \\
\hline \multirow{4}{*}{$\begin{array}{c}\text { Academic } \\
\text { Effort }\end{array}$} & $\rightarrow$ & $\mathrm{AE} 1$ & 1.000 & 0.806 & - & \multirow{4}{*}{.896} & \multirow{4}{*}{.682} & \multirow{4}{*}{.895} \\
\hline & $\rightarrow$ & AE2 & 1.046 & 0.848 & $17.180^{* * *}$ & & & \\
\hline & $\rightarrow$ & $\mathrm{AE} 3$ & .955 & 0.812 & $16.217 * * *$ & & & \\
\hline & $\rightarrow$ & $\mathrm{AE} 4$ & 1.059 & 0.837 & $16.886^{* * *}$ & & & \\
\hline \multicolumn{9}{|c|}{$\chi^{2}=6.218 \mathrm{df}=2, \mathrm{p}<.045, \mathrm{TLI}=.983, \mathrm{CFI}=.994, \mathrm{RMSEA}=.081, \mathrm{SRMR}=.014$} \\
\hline \multirow{3}{*}{$\begin{array}{c}P \cdot E \\
\text { Class Flow }\end{array}$} & $\rightarrow$ & cognitive flow & 1.000 & 0.832 & - & \multirow{3}{*}{.846} & \multirow{3}{*}{.647} & \multirow{3}{*}{.844} \\
\hline & $\rightarrow$ & emotional flow & 1.161 & 0.803 & $15.346^{* * *}$ & & & \\
\hline & $\rightarrow$ & behavioral flow & 1.100 & 0.778 & $14.837 * * *$ & & & \\
\hline
\end{tabular}




\section{3. 연구절차}

자료 수집은 2019년 10월부터 11월말까지 설문조사를 통해 이루어졌다. 설문조사를 위해 학교 현장에 직접 방문하 여 참여자(학생)에게 자발적 참여의사를 묻는 동의서를 받았 다. 이후 본 연구의 목적과 기대효과에 대한 내용을 충분히 설명하였고, 수집된 자료는 연구목적으로만 사용되며 참여 자의 개인적 정보는 노출되지 않는다는 등의 내용을 언급하 였다. 설문조사에는 연구자를 포함하여 보조원(석사) 2 명이 함께 진행하였으며, 솔직한 응답을 당부하였다. 연구자는 참 여들을 위해 소정의 기념품(학교로고 볼펜)을 제공하였다. 자 료 검토 분석과정을 통해 최종 323 부의 자료를 활용하였다.

\section{4. 자료처리 방법}

본 연구에서는 SPSS 24.0 프로그램을 활용하여 빈도 분 석, 신뢰도 분석, 기술통계 분석 및 상관 분석을 실시하였으 며, Amos 22.0 프로그램을 활용하여 확인적 요인분석 (confirmatory factor analysis), 측정모형(measurement model)분석, 구조모형(structural model)분석 그리고 Bootstrap방법을 활용한 매개효과 검증을 실시하였다. 통 계적 유의수준은 $\alpha=.05$ 로 설정하였다.

\section{5. 측정도구의 집중타당도 검증}

$\mathrm{SEM}$ 의 장점은 첫째, 측정변수(measured variable)를 이용해서 추출된 공통변량을 잠재변수(latent variable)로 사용하기 때문에 측정오차(measurement error)를 고려한 다. 둘째, 매개변수(mediator variable)를 쉽게 다룰 있다
는 점과 셋째, 측정과 이론구축을 동시에 할 수 있기 때문에 연구자가 관심을 갖고 있는 현상을 보다 정확하게 파악할 수 있다(Bae, 2017; Hong, 2000).

본 연구에서는 2단계분석(tow-step approach) 즉, 이론 모형이 자료에 얼마나잘 부합되는가를 평가하는 측정모형을 통해 가설을 검증하는 구조모형 분석을 실시하였다. 이에 부 모의 자율성지지와 교사의 자율성지지를 독립변인으로 설정 하고 즐거움, 자기효능감, 학습노력은 매개변인으로 그리고 종속변인으로 수업몰입을 설정하였다. 또한 학생들의 부모 의 자율성지지, 교사의 자율성지지, 즐거움, 자기효능감, 학 습노력, 그리고 수업몰입에 대한 집중타당도(convergent validity)를 검증하였다〈Table 2〉. 각 잠재변인의 개념신뢰 도(construct reliability: CR)의 경우 .921-.846까지 나타 나 기준치 $(\geq .70)$ 를 상회하였으며, $\mathrm{AVE}$ (평균분산추출; average variance extracted)는 .682-.593으로 기준치 ( $\geq .50)$ 를 상회하는 것으로 나타나 집중타당도에 문제가 없 는 것을 확인하였다(Fornell \& Larcker, 1981).

\section{연구결과}

\section{1. 기술통계 및 상관분석}

측정모형 평가를 통해서 선정된 최종 자료에 대한 평균 (M)과 표준편차(SD)의 기술통계분석을 실시하였다<Table 3). 그 결과 즐거움 $(\mathrm{M}=4.00)$, 자기효능감 $(\mathrm{M}=3.97)$, 학습 노력( $\mathrm{M}=3.95)$, 부모의 자율성지지(M=3.91), 교사의 자율성

Table 3. Result of the descriptive statistics, correlations and discriminant validity analysis

\begin{tabular}{lccccccccc}
\hline \hline \multicolumn{1}{c}{ Variable } & $\mathrm{M}(\mathrm{SD})$ & Skewness & Kurtosis & 1 & 2 & 3 & 4 & 5 & 6 \\
\hline 1. $\mathrm{PAS}(\rho 2)$ & $3.91(\mathrm{SD}=.81)$ & -.719 & .375 & .593 & & & & & \\
2. $\mathrm{TAS}(\rho 2)$ & $3.84(\mathrm{SD}=.85)$ & -.492 & -.244 & $.450(.16)$ & .626 & & & & \\
3. Enjoyment(P2) & $4.00(\mathrm{SD}=.79)$ & -.528 & -.030 & $.227(.05)$ & $.233(.05)$ & $.629(.39)$ & & & \\
4. Self-Efficacy(P2) & $3.97(\mathrm{SD}=.77)$ & -.476 & -.210 & $.275(.07)$ & $.320(.10)$ & $.631(.39)$ & .657 & & \\
5. Academic Effort(P2) & $3.95(\mathrm{SD}=.80)$ & -.435 & -.231 & $.159(.02)$ & $.296(.08)$ & $.558(.31)$ & $.615(.37)$ & .682 & \\
6. P.E Class Flow(P2) & $3.52(\mathrm{SD}=.75)$ & -.033 & -.345 & $.367(.13)$ & $.503(.25)$ & $.377(.14)$ & $.397(.15)$ & $.537(.28)$ & $.647(.41)$ \\
\hline \hline
\end{tabular}

$* * p<.01$ 
지지(M=3.84), 그리고 수업몰입( $\mathrm{M}=3.52)$ 순으로 평균점 수가 높았으며, 각 요인 모두 왜도와 첨도가 기준치(왜도 $\geq .20$, 첨도 $\geq .30$ )에서 문제가 확인되지 않아 데이터의 정 규성가정이 충족되었다.

한편, 다중공선성(multicollinearity) 여부를 확인하기 위해 상관관계를 확인하였다〈Table 3〉. 추정결과, 부모의 자율성지지는 교사의 자율성지지(r=.450), 즐거움( $(r=.227)$, 자기효능감(r=.275), 학습노력(r=.159), 그리고 수업몰입 (r=.367)에 정적인 상관을 나타냈으며, 교사의 자율성지지는 즐거움(r=.233), 자기효능감 $(r=.320)$, 학습노력(r=.296), 그리고 수업몰입(r=.503)에 정적인 상관을 나타나냈다. 한 편, 즐거움은 자기효능감 $(\mathrm{r}=.631)$, 학습노력(r=.558), 그리 고 수업몰입(r=.377)에 정적인 상관을 나타나냈고, 자기효 능감은 학습노력(r=.615), 그리고 수업몰입(r=.397)에 정 적인 상관을 나타나냈다. 마지막으로 학습노력은 수업몰입 (r=.647)에 정적인 상관을 나타나냈다. 본 연구에서는 변인 간의 상관이 .80보다 낮아 수용할 수 있는 수준으로 판단하 였다(Kline, 2011).

\section{2. 측정모형 평가}

대부분의 연구자들은 관측변수의 신뢰도는 구조모형과 측정모형이 상호작용이 되지 않는 2 단계분석에서 정확히 추정된다고 보기 때문에 2단계접근법(two-step approach) 이 선호된다.

측정모형을 설정함에 있어 부모의 자율성지지, 교사의 자 율성지지, 즐거움, 자기효능감, 학습노력 변인은 해당 잠재 변수가 측정모형을 설명하도록 설정하였다. 다만 수업몰입 변인의 경우 선행연구에서 제시한 하위요인(인지몰입, 감성 몰입, 행동몰입)을 중심으로 항목묶음(item parceling)을 하였다(Kline, 2011). 측정모형의 검증결과 $\chi^{2}=832.624$, $\mathrm{df}=362, p<.000, \mathrm{TLI}=.915, \mathrm{CFI}=.924$, RMSEA $=.064$, $\mathrm{SRMR}=.043$ 으로 적합도 지수는 기준치를 충족할 수 있는 수준으로 나타났다. 관측변수 모두 표준요인부하량 (standardized factor loading)은 .50이상으로 나타났다. 측정모형의 추정방법은 최대우도법(Maximum Likelihood) 을 적용하였고, 지수의 적합기준은 Hair, Black, Babin, Anderson, \& Tatham(2006)이 추천하고 있는 $\chi^{2}$ (i.e. 표 본수의 영향을 받을 수 있음), CFI, TLI, RMSEA와 SRMR지 수 값을 동시에 적합기준으로 선정하였다. TLI(Tucker-
Lewis index)와 CFI(comparative fit index)의 경우 .90 이상이면 좋은 적합도 지수로 받아들여지며, RMSEA와 SRMR의 경우에는 .08 이하일 때를 수용할 수 있는 수준으 로 해석하였다(Bae, 2017).

한편, 〈Table 3〉에 각 개념들 간의 상관계수 및 상관계수 제곱의 크기와 방향이 제시되어 있다. 또한 $\mathrm{AVE}$ 값이 전체적 으로 개념 간 상관계수 제곱값 $\left(\phi^{2}\right)$ 보다 큰 것으로 확인되었 다. 따라서 판별타당성 또한 문제가 없는 것(AVE > 상관계수 2)으로 나타나 전체적으로 본 연구에서 측정하고자 하는 연 구모형에 대한 타당도는 확보되었으며, 전반적으로 측정모 형이 우수(Anderson \& Gerbing, 1988)하므로 구조모형 검증을 진행하였다.

\section{3. 연구모델 내 변인들의 관계}

구조모형의 총 효과 및 직접효과 그리고 직·간접효과를 분석한 결과는 〈Table 4,5 〉와 같다. 설정된 가설을 통계적 으로 수용할 것인지, 기각할 것인지를 판단하기 위해 구조 모형 검증을 실시하였다. 모형의 적합성을 판단한 결과, $\chi^{2}$ $=841.512$, 자유도 $(\mathrm{df})=366, \quad \mathrm{TLI}=.915, \quad \mathrm{CFI}=.951$, $\mathrm{RMSEA}=.064, \mathrm{SRMR}=.045$ 값으로 나타났다. 적합지수는 Hair et al.(2006)이 추천하는 기준을 충족하고 있으므로 설정된 모형을 적합하다고 판단하였다.

상정된 각 변인 간 경로의 관계를 살펴본 결과는 〈Table $4>$ 와 같다. 첫째, 부모의 자율성지지는 즐거움에 정적으로 유의한 영향을 미치는 것으로 나타났다( $\beta=.145, p<.05)$. 둘 째, 교사의 자율성지지는 즐거움에 정적으로 유의한 영향을 미치는 것으로 나타났다( $\beta=.193, p<.01)$. 셋째, 부모의 자 율성지지는 자기효능감에 정적으로 유의한 영향을 미치는 것으로 나타났다( $\beta=.162, p<.05)$. 넷째, 교사의 자율성지지 는 자기효능감에정적으로 유의한 영향을 미치는 것으로 나 타났다 $(\beta=.273, p$ 〈.001). 다섯째, 즐거움은 학업노력에 정 적으로 유의한 영향을 미치는 것으로 나타났다 $(\beta=.291, p$ 〈.001).

여섯째, 자기효능감은 학업노력에 정적으로 유의한 영 향을 미치는 것으로 나타났다( $\beta=.482, p<.001)$. 일곱째, 학업노력은 수업몰입에 정적으로 유의한 영향을 미치는 것 으로 나타났다 $(\beta=.482, p<.001)$. 다음으로 부모의 자율성 지지는 수업몰입에 정적으로 유의한 영향을 미치는 것으로 나타났다( $\beta=.166, p<.01)$. 마지막으로 교사의 자율성지지 
는 수업몰입에 정적으로 유의한 영향을 미치는 것으로 나 타났다 $(\beta=.349, p<.001)$.

Table 4. Direct and indirect effects

\begin{tabular}{lccc}
\hline \hline \multicolumn{1}{c}{ Path } & $\begin{array}{c}\text { Direct } \\
\text { Effect }\end{array}$ & $\begin{array}{c}\text { Indirect } \\
\text { Effect }\end{array}$ & $\begin{array}{c}\text { Total } \\
\text { Effects }\end{array}$ \\
\hline PAS(A) $\rightarrow$ Enjoyment(B) & .169 & - & $.169^{*}$ \\
TAS(B) $\rightarrow$ Enjoyment(C) & .192 & - & $.192^{* *}$ \\
PAS(A) $\rightarrow$ Self-Efficacy(C) & .182 & - & $.182^{*}$ \\
TAS(B) $\rightarrow$ Self-Efficacy(C) & .262 & - & $.262^{* * *}$ \\
Enjoyment $\rightarrow$ Academic Effort & .272 & - & $.272^{* * *}$ \\
Self-Efficacy $\rightarrow$ Academic Effort & .465 & - & $.465^{* * *}$ \\
Academic Effort $\rightarrow$ P.E Class Flow & .420 & - & $.420^{* * *}$ \\
$\dagger$ PAS(A) $\rightarrow$ P.E Class Flow (C) & .157 & .055 & $.212^{* * *}$ \\
$\dagger$ TAS(A) $\rightarrow$ P.E Class Flow (C) & .282 & .073 & $.355^{* *}$ \\
\hline \hline
\end{tabular}

Note. PAS; Parent A-S, TAS; Teacher A-S

${ }^{* *} p<.01,{ }^{* * *} p<.001$

\section{4. 구조모형에서 간접효과의 유의성 검증}

분석된 결과를 종합적으로 살펴보면, 부모의 자율성지 지는 즐거움과 자기효능감에 정적인 직접효과를 미치고 즐거움과 자기효능감은 학업노력에 그리고 학업노력은 수 업몰입에 정적인 직접효과가 나타났다. 또한 교사의 자율 성지지는 즐거움과 자기효능감에 정적인 직접효과를 미치 고 즐거움과 자기효능감은 학업노력에 그리고 학업노력은 수업몰입에 정적인 직접효과가 나타났다. 이상과 같이 각 경로의 통계적 유의성을 검증한 결과를 통해, 부모의 자율 성지지 및 교사의 자율성지지는 즐거움, 자기효능감, 학업 노력의 효과를 거쳐 수업몰입을 설명하는 간접효과가 존 재함을 확인할 수 있었다. 이를 통해 부모의 자율성지지 및 교사의 자율성지지와 즐거움, 자기효능감, 학업노력의 관 계에서 수업몰입의 매개효과를 통계적으로 검증할 필요가 있음이 확인되었다(Kline, 2011). 따라서 수업몰입의 간 접효과(매개효과)가 통계적으로 유의한가를 검증하기 위 하여 Bootstrap 방법을 활용하였고(Shrout \& Bolger, 2002), 이때 반복수행은 2,000번, 통계적 유의성은
Bias-corrected confidence intervals의 95\% 신뢰구간 에서 확인하였다〈Table 5〉.

Table 5. Results of mediation effects

\begin{tabular}{|c|c|c|c|c|}
\hline \multirow{2}{*}{$\begin{array}{l}\text { Standardized } \\
\text { Indirect } \\
\text { Effect }\end{array}$} & \multirow[b]{2}{*}{ S.E } & \multirow[b]{2}{*}{ Sig } & \multicolumn{2}{|c|}{ Bootstrapping } \\
\hline & & & $\begin{array}{l}\text { BC 95\% } \\
\text { CI Lower }\end{array}$ & Upper \\
\hline$\dagger .058$ & .026 & $.018^{*}$ & .010 & .115 \\
\hline \pm .091 & .031 & $.002 * *$ & .033 & .154 \\
\hline
\end{tabular}

${ }^{*} p<.05,{ }^{* *} p<.01$

Note: Bootstrap Sample $=2,000$

$\dagger$ PAS $\rightarrow$ enjoyment, self-efficacy, academic effort $\rightarrow \mathrm{p} \cdot \mathrm{e}$ class flow

$\ddagger$ TAS $\rightarrow$ enjoyment, self-efficacy, academic effort $\rightarrow \mathrm{p} \cdot$ e class flow

부트스트래핑을 통해 부모의 자율성지지와 수업몰입 그 리고 교사의 자율성지지와 수업몰입의 관계에서 간접효과 (즐거움, 자기효능감, 학업노력)의 유의성을 검증한 결과는 〈Table 5〉와 같다. 분석결과 부트스트래핑을 통해 추정된 매개효과 계수의 하한한계(lower bounds)는 각각 .010(부 모의 자율성지지와 수업몰입의 관계)과 .027(교사의 자율 성지지와 수업몰입의 관계), 상한한계(upper bounds)는 각각 . 110 (부모의 자율성지지와 수업몰입의 관계)과 .129 (교사의 자율성지지와 수업몰입의 관계)로, 0 을 포함하지 않았다. 따라서 부모의 자율성지지 $\rightarrow$ 즐거움, 자기효능감, 학업노력 $\rightarrow$ 수업몰입의 간접효과 $(\beta=.058, p<.05)$ 와 교사 의 자율성지지 $\rightarrow$ 즐거움, 자기효능감, 학업노력 $\rightarrow$ 수업몰 입의 간접효과 $(\beta=.091, p$ 〈.01)가 통계적으로 유의한 것으 로 나타나 부분매개효과가 있는 것으로 확인되었다.

\section{논 의}

본 연구는 체육수업에 참여한 중학생이 지각한 부모의 자 율성지지 및 교사의 자율성지지와 즐거움, 자기효능감, 학업 노력, 그리고 수업몰입의 관계를 살펴보고 부모의 자율성지 지 및 교사의 자율성지지와 수업몰입의 관계에서 즐거움, 자 기효능감, 학업노력의 매개효과를 검증하였다. 따라서 이론 적 근거와 실증적 자료를 기초로 상정된 연구가설을 체계적 
으로 분석한 연구결과를 바탕으로 다음과 같이 논의하였다. 첫째, 부모의 자율성지지 및 교사의 자율성지지와 즐거움 의 관계를 분석한 결과, 부모의 자율성지지 $(\beta=.169)$ 및 교사 의 자율성지지 $(\beta=.192)$ 는 즐거움에 모두 정적으로 영향을 미쳤다. 결과에서 확인된 것처럼 체육수업에 참여한 학생들 은 부모의 자율성지지보다 교사의 자율성지지가 수업에서 느끼는 즐거움에 더 영향을 미치는 것으로 확인되었다. 이러 한 결과는 Yang, Lee(2011)의 연구결과로 설명할 수 있다. 그들은 방과 후 특기(무용)적성교육 프로그램과 무용학원에 수강하고 있는 초등학생을 대상으로 부모와 교사의 자율성 지지와 재미/즐거움과의 관계에서 교사 $\beta=.043)$ 보다 부모 ( $\beta=.398)$ 의 자율성지지가 재미/즐거움을 더 강하게 예측하 는 것으로 확인되었다. 선행연구의 경우 무용학원과 방과 후 적성교육 프로그램이 무용의 구성되어 있다는 공통성으로 인하여 이와 같은 결과를 얻은 것으로 보인다. 다만 이 연구 에서는 체육수업이라 환경의 특수성과 인지 능력이 형성된 중학생이라는 것을 고려할 때, 학생들과 직접적으로 관계를 맺고 활동하는 일차적 관계가 교사 또는 동료들이라는 측면 에서 즐거움에 미치는 영향이 부모의 자율성지지보다 교사 의 자율성지지가 크다는 점은 충분히 이해할 만하다.

Reeve et at.(2004)에 의하면 자율성지지는 개인의 흥 미, 호기심, 유능성, 자율성 등의 내재적 자원을 이끌어 내 고, 행동을 촉진하도록 돕는 사회적 행동으로 언급하였다. 이러한 관점에서 교사의 자율성지지로부터 만족된 학생들은 즐거움(Shen et al., 2010)뿐만 아니라 긍정적 정서의 경험 (Taylor \& Lonsdale, 2010), 자결성동기(Ntoumanis, 2005; Standage, Duda, \& Ntoumanis, 2006), 재미 와 신체활동 향상(Cox, Duncheon, \& McDavid, 2009; Cox, Smith, \& Williams, 2008), 바람직한 학업 행동(Cho, 2011; Reeve et al., 2004)에 직.간접적으로 관련이 있다.

따라서 체육수업에 참여하는 학생들이 즐거움뿐만 아니 라 동기유발 및 긍정적 정서, 바람직한 학업행동 나아가 행 복감 등을 능동적으로 이끌어 내거나 경험하기 위해서는 교 사의 자율성지지 또는 그 역할이(가) 무엇보다 중요하다는 것을 이 연구를 통해 확인하였다.

둘째, 부모의 자율성지지 및 교사의 자율성지지와 자기 효능감의 관계를 분석한 결과, 부모의 자율성지지 $(\beta=.182)$ 및 교사의 자율성지지 $(\beta=.262)$ 는 자기효능감에 모두 정적 으로 영향을 미쳤다. 결과에서 확인된 것처럼 체육수업에
참여한 학생들은 부모의 자율성지지보다 교사의 자율성지 지가 자기효능감에 더 큰 영향을 미치는 것으로 확인되었 다. 학생들마다 개인적 차이는 있겠지만 보편적으로 학습 자의 자기효능감 향상을 위해서는 교사의 자율성지지가 선 행되어야 한다. 이러한 결과는 $\mathrm{Cho(2018)이} \mathrm{보고한} \mathrm{연구}$ 결과와 맥을 같이한다. 선행연구에 따르면 교사의 자율성 지지는 자기효능감에 직접적으로 영향을 미치는 것으로 나 타났는데 이는 학습 상황에서 학생들과의 소통을 주요 원 인으로 보고하였다. 체육수업에서 소통의 주체가 교사와 학습자 그리고 학습자와 학습자라는 점에서 교사의 자율성 지지는 학습자의 과제를 수행하기 위한 기술 향상에 도움 을 제공할 것이다(Cheon, Reeve, \& Moon, 2012).

자기효능감이 개인이 가진 스스로의 역량에 대한 신념이 라는 점을 고려할 때, 체육수업 상황에서 교사의 자율성지 지는 학생 개인의 역량을 충분히 발휘하여 과제를 성공적으 로 달성할 수 있을 것이라는 예측이 가능하다. Park(2010) 에 의하면 교사와 학생과의 관계는 학교적응에 중요한 요인 이 되며, 자율성을 지지하는 수업에서 교사의 의사소통은 학생의 내적 동기를 유발하고, 자발적 참여를 촉진(Black \& $\mathrm{Deci}, 2000)$ 한다. 교사가 학생에게 관심을 갖고 즐거움과 흥미 그리고 수행 향상을 위해 도움을 준다면 학생의 자기효 능감은 높아져 체육수업 참여에 자발성을 띨 것이다. 이는 결과적으로 학생의 자발적 참여는 교사의 자율성지지로 인 해 자기효능감이 높아질 때 가능성이 높이기 때문에 교사는 학생들의 자율권을 보장하는 체육수업 환경 조성과 동시에 학생들의 자기효능감을 높은 수준으로 향상시킬 수 있는 수 업환경에 대한 고려가 필요하다.

셋째, 즐거움과 자기효능감은 학업노력에 정적인 영향을 미쳤다. 이는 체육수업에 참여하는 학습자들이 체육수업에 대한 즐거움과 자기효능감이 높을수록 학업에 대한 노력을 더욱 기울이는 것으로 이러한 결과는 $\mathrm{Lyu}(2011)$ 의 연구와 맥을 같이 하며, 또한 Cho(2017)의 연구를 통해 근거를 확 보할 수 있다. 학습자의 관점에서 체육수업에 대해 가치 있 고, 즐겁고, 보람이 있다고 인지하거나 혹은 지루하거나 가 치가 없다고 인지할 경우 학습자들은 두 측면에 대한 경험을 결정할 수 있는 속성을 가지고 있기 때문에 인지적 및 동기 적 과정을 이해하는 것은 매우 중요하다(Kim, Cho, Won, 2013). 학생들이 지각하는 즐거움은 긍정적인 감정으로 지 속적인 참여를 이끄는 단초가 될 수 있다. 수업 참여에서 즐 거움이 높으면 능동적으로 참여하고, 이는 학습자들의 내적 
동기를 충족하여 학습에 더 적극적으로 참여하게 될 것이 다. 수업에서 교사의 칭찬과 격려는 학습자가 수업(과제)에 더욱 적극적으로 참여하게 하는 열의를 유발하게 한다 (Koka \& Hein, 2003; Nicaise et al., 2007). 이는 결과적 으로 체육수업에 참여하는 학생들의 높은 자기효능감이 학 업에 더욱더 열심히 노력한다는 결과를 예측할 수 있는 근거 로 작용될 것이다.

Pekrun(2006)에 의하면 자기효능감은 운동학습참여와 밀접한 관련이 있기 때문에 신체활동에 참여하는 참여자들 이 학습을 지속하는데 자기효능감은 중요하게 작용한다고 보고하였다. 학습자들은 체육수업 상황에서 특정한 과제를 수행함에 있어서 실패를 경험할 수도 있고 반면, 성공을 경 험할 수 있다. 이러한 과정에서 교사의 자율성지지는 학습 자들의 자기효능감을 높이기 때문에 실패를 경험하더라도 좌절하기보다 더 노력하고 끈기 있게 과제를 지속하는데 중 요한 역할을 한다. 또한 자기효능감은 효능기대(efficacy expectation)라고도 하며, Bandura는 자기효능감과 함께 결과기대(outcome expectation)라는 개념을 도입했다 (Schukajlow et al., 2012). 이 개념에 비추어볼 때, 학습자 들이 체육수업에서의 과제를 평가할 때 얼마나 가치가 있는 지 그리고 그 과제에 대해 얼마나 잘 해낼 수 있는지에 대한 자기 평가 수준이 과제에 대한 선택 및 지속과 함께 관여 수 준을 결정하기 때문에 학업노력을 예측하는 강력한 선행변 인으로 언급된다. 특히 Chase(2001)의 연구에서는 자기효 능감 수준이 노력의 정도에 영향을 미치는 것으로 확인되었 고, Boiche et al.(2008)은 자기효능감수준은 높은 수준의 노력과 밀접한 관계가 있음을 증명하였다. 학습자의 자기효 능감은 교사로부터 강력한 영향을 받는 것으로 알려져 있다 (Vargas-Tonsing, Warners, \& Feltz, 2003).

따라서 체육수업 상황에서 학습자의 높은 자기효능감은 노력과 지속행동에 긍정적 영향을 미치므로 학습자들의 학 업노력을 이끌어 내기 위해서는 자기효능감을 향상시키기 위한 노력이 무엇보다 중요하다는 사실을 이 연구를 통해 확인하였다.

넷째, 이 연구에서 상정한 학업노력과 수업몰입의 관계 에서 학업노력은 수업몰입에 정적인 영향을 미쳤다. 이는 체육수업에 참여하는 학습자들이 체육수업 상황에서 학업 에 대한 노력을 많이 투여할 경우 과제 수행이나 스포츠 활 동에 몰두하는 것으로 확인되었다. 이러한 결과는 Song(2003)의 연구와 맥을 같이 하며, 또한 David
Bowman, Keene, \& Najera(2021)의 연구를 통해 근거 를 확보할 수 있다.

체육수업 상황에서 학업적 노력은 과제를 지속하기 위 해 인내하고 성실하게 과제를 수행해 나가는 것으로 이야 기할 수 있다(Nam, 2015; Cho, 2017; Zimmerman \& Martinez-Pons, 1990). 또한 Shin, Jin(2013)는 학업을 수행하면서 학습자가 스스로 얼마나 끈기 있게 노력을 하 는지, 또는 학업 상황에서 어려움에 직면하더라도 이를 극 복하고자 최선을 다하는지 등으로 언급하였다. 청소년들의 신체활동과 체육교육의 중요성이 지속적으로 강조되고 있 는 시점에서 체육수업을 통해 즐거움을 느끼고, 최상의 경 험과 더불어 수업에 대한 만족감이 충족될 경우 수업에서 의 몰입을 경험할 수 있다. 이런 몰입의 경험은 애써 노력하 여 일어나는 것이 아니라 과제에 대한 즐거움과 흥미로 인 해 자연스럽게 나타난다. 따라서 학습자들은 체육수업 참 여시 주어진 과제를 성공적으로 달성하기 위한 분명한 목 표설정이 필요하고 이러한 목표가 있는 활동은 노력을 이 끌어내 몰입을 경험할 수 있다.

무엇보다 체육수업에서 교사 또는 동료들과의 효과적인 유대관계는 학습자의 자발적 참여 행동을 유발하게 만들고 또한 목표를 성취하기 위해 구성원들과의 협동은 강력한 노 력을 이끌어낼 것이다. 이러한 행위에 관한 노력은 결과적 으로 체육수업에서의 몰입을 촉진시킬 것이다. 이에 체육수 업에서 학습자들의 몰입 경험을 증진 시기키 위해서는 학습 자의 강력한 노력을 이끌어 내는 것이 중요하며, 이런 학습 자의 노력은 교사의 능력이나 유대감 형성과 함께 명확한 목 표설정 등을 통해 이끌어 낼 수 있을 것이다.

마지막으로 부모의 자율성지지 그리고 교사의 자율성지 지와 수업몰입의 관계에서 즐거움, 자기효능감, 그리고 학 업노력의 매개효과를 검증한 결과, 즐거움, 자기효능감, 그 리고 학업노력은 부모의 자율성지지 $(\beta=.058)$ 와 수업몰입 과의 관계에서 부분매개효과 나타난 것보다, 교사의 자율 성지지 $(\beta=.091)$ 와 수업몰입과의 관계에서 부분매개효과 더 강하게 나타났다. 이러한 결과는 앞서 언급한 것처럼 체 육수업이라는 환경의 특수성과 인지능력이 형성된 중학생 이라는 점을 고려할 필요가 있다. 체육수업에서 학습자들 과 직접적으로 관계를 맺고 활동하는 일차적 관계가 교사 또는 동료들이라는 점은 학습자의 수업몰입을 촉진하는데 있어 부모의 자율성지지보다 교사의 자율성지지가 더 크게 작용한다는 점은 충분히 이해할 만하다. 무엇보다 교사의 
자율성지지는 학생들의 긍정적인 감정을 형성하기 때문에 학생들과 효과적인 관계를 유도할 뿐만 아니라 내적동기가 형성될 가능성이 높다. 따라서 대인관계 관점에서 긍정적 으로 형성된 동기는 미래지향적 측면에서 학습자들의 대인 관계(학생과 교사 그리고 동료들 간의 관계)를 유지하고 더 긍정적이고 강한 신념을 갖게 할 것이며, 이를 바탕으로 과 제 참여에 대한 도전과 학습노력 등 실제 수행을 강력하게 예측할 것이다.

청소년기 학생들이 성장하는 과정에서 개인의 인지, 정 서, 행동적 적응은 환경적 특성(Deci \& Ryan, 2000)에 따 라 좌우되기 때문에 이 시기 학생들의 발달에 중요한 역할 을 하는 부모와 교사(Van der Kaap-Deeder et al., 2017)의 자율성지지 특히, 교사의 자율성 지지는 수업 상 황에서 학생들에게 자기주도와 선택의 기회를 제공한다 (Vansteenkiste, Lens, \& Deci, 2006). 따라서 이 상태 (자율성지지 경험)에 있는 학생들은 본질적으로 동기를 부 여받기 때문에 자신의 잠재력을 실현할 수 있는 가능성이 크며, 점진적으로 더 큰 도전을 추구할 수 있을 것이다. 이 러한 측면에서 체육수업에서 학습자들의 즐거움과 자기효 능감 향상에 대한 기대는 교사의 자율성지지로부터 제공받 게 되며, 이는 체육수업에 더욱 적극적으로 참여하려는 학 습노력을 이끌어내 체육수업에서의 몰입경험을 예측할 수 있다는 사실을 본 연구를 통해 확인되었다.

\section{결론 및 제언}

본 연구는 교육적 관점에서 실용적 지식을 제공하기 위한 목적으로 부모와 교사의 자율성지지와 즐거움, 자기효능감, 학업노력 그리고 수업몰입의 관계를 확인하고, 또한 즐거 움, 자기효능감, 그리고 학업노력이 부모의 자율성지지 및 교사의 자율성지와 수업몰입의 관계에서 어떠한 매개효과 가 있는지를 알아보고자 하였다. 결론적으로 부모의 자율성 지지보다 교사의 자율성지지와 수업몰입 관계에서 즐거움, 자기효능감, 그리고 학업노력의 매개효과가 더 강력한 것으 로 확인되었다. 따라서 교사는 학생들의 수업몰입을 증진 시키기 위해 학습자로 하여금 자발적이고, 자기주도적 참여 를 이끌어 내는 즉, 자율성을 지지하는 수업방식을 제공할 필요가 있으며, 더불어 체육수업에서 학습자가 도전하고, 끈기 있게 노력할 수 있도록 심리적 즐거움과 자기효능감을
높이는 수업 프로그램을 제공함으로써 학생들은 수업몰입 을 경험할 것이다. 이는 향후 수업몰입을 경험하는데 유용 한 방안이 될 수 있을 것이다.

한편, 미래지향적 측면에서 많은 학생들이 체육수업을 좋아하고, 기다려지며, 더 선호할 수 있는 환경을 마련하고, 나아가 건강한 정신과 신체를 유지할 수 있도록 하는 것도 교사로서 그 역할이 중요하게 작용된다는 사실도 이해할 필 요가 있다. 이를 위해 교사들의 인식 성향과 성(남자, 여자) 차이가 수업노력이나 수업몰입에 중요한 요인으로 작용될 수 있는지를 심층적으로 알아보기 위해 보다 광범위한 차원 에서 교사와의 심층면담 등 다양한(질적, 양적, 혼합) 연구 방법을 적용한 연구가 진행될 필요가 있다. 또한 체육수업 에 자발적으로 참여하는 학생들은 대부분 적극적이고 열정 적인 태도를 지니고 있다. 때문에 학습자들이 체육수업에서 일시적으로 역경에 직면했을 경우 이를 슬기롭게 대처할 수 있는 프로그램을 개발하여 제공한다면 체육수업 참여에 대 한 흥미 및 적극적 참여를 이끌어 내기 위한 효율적 정보를 제공할 수 있을 것으로 기대된다.

\section{참고문헌}

Anderson, J. C., \& Gerbing, D. W. (1988). Structural equation modeling in practice: A review and recommended two-step approach. Psychological Bulletin, 103(3), 411-423.

Aunola, K., \& Nurmi, J. E. (2004). Maternal affection moderates the impact of psychological control on a child's mathematical performance. Developmental Psychology, 40(6), 965-978.

Bae, B. R. (2017). Structural equation modeling with Amos 24. Seoul, Unpublished Chungram.

Bandura, A. (1977). Self-efficacy: toward a unifying theory of behavioral change. Psychological review, 84(2), 191-215.

Bandura, A. (1997). Self-efficacy: the exercise of control. New York, NY: Freeman.

Black, A. E., \& Deci, E. L. (2000). The effects of instructors' autonomy support and students' autonomous motivation on learning organic chemistry: A self determination theory perspective. Science Education, 84(6), 740-756.

Boich, J. C. S., Sarrazin, P.G., Grouzet, F. M. E., Pelletier, L. G., \& Chanal, J. P.(2008). Students' motivational profiles 
and achievement outcomes in physical education: $\mathrm{A}^{\text {self }}$ determination perspective. Journal of Educational Psychology, 100, 688-701.

Brustad, R. J. (1993) Youth in sport: Psychological considerations. In: Handbook of Research on Sport Psychology, R.N. Singer, M. Murphy, and L.K. Tennant (Eds.). New York: Macmillan, pp. 695-717.

Chase, M. A. (2001). Children's self-efficacy, motivational intentions, and attributions in physical education and sport. Research Quarterly for Exercise and Sport, 72(1), 47-54.

Chen, C. (2006). CiteSpace II: Detecting and visualizing emerging trends and transient patterns in scientific literature. Journal of the American Society for information Science and Technology, 57(3), 359-377.

Cheon, S. H., Reeve, J., \& Moon, I. S. (2012). Experimentally based, longitudinally designed, teacher-focused intervention to help physical education teachers be more autonomy supportive toward their students. Journal of Sport and Exercise Psychology, 34(3), 365-396.

Cheon, S. H., Reeve, J., \& Vansteenkiste, M. (2017). An intervention to enhance both autonomy support and structure in physical education teachers' classroom motivating style. Manuscript submitted for publication.

Cho, H. S. (2011). The Effect of Teachers' Autonomy Support Environment in Physical Education on Students' Help-seeking Behaviors and Class Participation Attitude. Korean journal of physical education, 18(1), 17-32.

Cho, P. H. (2018). The Structural relationship between teachers autonomic support, students self-efficacy, passion, and engagement of physical education classes in elementary school. Korean Society For The Study Of Physical Education 23(1), 93-105.

Cho. H. S. (2017). The Effects of Students'Academic Engagement for Physical Education Classes on Their Academic Effort and Class Participation Attitude. Korean Journal of Sports Science 26(4), 745-760.

Coates, H. (2006). Student engagement in campus-based and online education, New york: Routledge.

Cox, A., Smith, A., \& Williams, L. (2008). Change in physical education motivation and physical activity behavior during middle school. Journal of Adolecsent Health, 43, 506-513.

Csikszentmihalyi, M. (1990). Flow: The psychology of
Optimal Experience. New York, N. Y.: Harper Perennial. David Bowman, N., Keene, J., \& Najera, C. J. (2021). Flow encourages task focus, but frustration drives task switching: How reward and effort combine to influence player engagement in a simple video game. In Proceedings of the 2021 CHI Conference on Human Factors in Computing Systems (pp. 1-8).

Deci, E. L., \& Ryan, R. M. (1980). The empirical exploration of intrinsic motivational processes. In Advances in experimental social psychology, 13, 39-80.

Deci, E. L., \& Ryan, R. M. (2000). The" what" and" why" of goal pursuits: Human needs and the self-determination of behavior. Psychological Inquiry, 11(4), 227-268.

Dishman, R. K., Motl, R. W., Sallis, J. F., Dunn, A. L., Birnbaum, A. S., Welk, G. J., ... \& Jobe, J. B. (2005). Self-management strategies mediate self-efficacy and physical activity. American journal of preventive medicine, 29(1), 10-18.

Fisher, C. D., \& Noble, C. S. (2004). A within-person examination of correlates of performance and emotions while working. Human Performance, 17, 145 - 168.

Fornell, C., \& Larcker, D. F. (1981). Evaluating structural equation models with unobservable variables and measurement error. Journal of Marketing Research, 18(1), 39-50.

Gao, Z., Lee, A. M., \& Harrison, L. (2008). Understanding students' motivation in sport and physical education: From the expectancy-value model and self-efficacy theory perspectives. Quest, 60(2), 236-254.

Gould, D. (1987). Understanding attrition in children's sport. In: Advances in Pediatric Sport Sciences, D. Gould and M.R. Weiss (Eds.). Champaign, IL: Human Kinetics, pp, 61-88.

Hagger, M. S., Chatzisarantis, N. L., Culverhouse, T., \& Biddle, S. J. (2003). The processes by which perceived autonomy support in physical education promotes leisure-time physical activity intentions and behavior: a trans-contextual model. Journal of educational psychology, 95(4), 784-795.

Hair, J. F., Black, W. C., Babin, B. J., Anderson, R. E., \& Tatham, R. (2006). Multivariate data analysis. Uppersaddle River.

He, Y. C. (2009). Self-determination among adult Chinese 
English language learners: The relationship among perceived autonomy support, intrinsic motivation, and engagement. Unpublished doctoral dissertation, University of Southern California.

Hong, S. H. (2000). The Criteria for Selecting Appropriate Fit Indices in Structural Equation Modeling and Their Rationales. Korean Journal of Clinical Psychology , 19(1), 161-177.

Hutchinson, J. C., Sherman, T., Martinovic, N., \& Tenenbaum, G.(2008). The effect of manipulated self-efficacy on perceived and sustained effort. Journal of Applied Sport Psychology, 20, 457-472.

Jackson, B., \& Beauchamp, M. R.(2010). Efficacy beliefs in athlete-coach dyads: Prospective relationships using actor-partner interdependence models. Applied Psychology: An International Review, 59, 220-242.

Kim, G. K., Cho, H. I., \& Won, M., A. (2013). The Effects of Physical Activity Pleasure on Intrinsic Motivation, Interest, and Flow of Physical Education Class. Korean Journal of Sports Science 22(4), 511-530.

Kim, M. S., Kim, G. K., \& Won, M. A. (2015). Effect of Physical Activity Pleasure on the Flow of Middle School Students : Analysis of Intermediating Effect of Intrinsic Motivation. Journal of Sport and Leisure Studies 61, 471-479.

Kline, R. B. (2011). Principles and practice of structural equation modeling (3rd ed.). NY: Guilford Press.

Koka, A., \& Hein, V. (2003). Perceptions of teacher's feedback and learning environment as predictors of intrinsic motivation in physical education. Psychology of sport and exercise, 4(4), 333-346.

Kom, J. B., \& Kim, T. E. (2008). The Development and Validation of Korean School Happiness Scale. The Korean Journal of Educational Psychology 22(1), 259-279.

Lee, H. R. (2013). The Relationship between Parental Autonomy Support and Psychological Control on the Psychosocial Adaptation: The Mediating Effects of Children's Self-Regulation Styles. Unpublished doctoral dissertation, DanKook University.

Lee, J. W., Cheon, S. H., Kim, B. R., \& Song, Y. G. (2017). Development and Validation of Multiple Motivating Styles Scale (MMSS). The Korean Journal of Measurement and Evaluation in Physical Education and Sport Science, 19(2),
45-57.

Lee, S. J. (2011). The effect of flow on learning and self-efficacy on college adaptation and academic achieve in undergraduate students. The Korean Journal of Educational Psychology, 25(2), 235-253.

Lyu, M. J. (2011). We Preferred Female Teacher in Physical Education(PE) Classes?: Focused on Exercise Interest, Class Effort, and Teacher Feedback Perceived in PE Classes. Korean Journal of Sport Science, 22(2), 1999-2007.

Marks, H. M. (2000). Students engagement in instructional activity : Patterns in the elementary, middle, and high school years. American educational Research Journal, 37(1), 153-184.

Nam, S. H. (2015). Development and Validation of an Academic Effort Scale. Unpublished master dissertation, Jeonbuk National University.

Nicaise, V., Bois, J. E., Fairclough, S. J., Amorose, A. J., \& Cogérino, G. (2007). Girls' and boys' perceptions of physical education teachers' feedback: Effects on performance and psychological responses. Journal of Sports Sciences, 25(8), 915-926.

Ntoumanis, N. (2005). A prospective study of participation in optional school physical education using a self-determination theory framework. Journal of Educational Psychology, 97, 444-453.

Ntoumanis, N., Barkoukis, V., \& Thøgersen-Ntoumani, C. (2009). Developmental trajectories of motivation in physical education: Course, demographic differences, and antecedents. Journal of Educational Psychology, 101(3), 717-728.

Park, C. N. (2010). A Study on the Effects of School Structure and School Organization on School Maladjustment. Journal of Future Oriented Youth Society, 7(3), 165-184.

Park, I. J., \& Cho, S. K. (2020). The Influence of Badminton Tournament on the Enjoyment, Satisfaction, and Intention to Revisit : Focused on Pine \& Gilmore's Experiential Economy Theory. Korean Journal of Sports Science, 29(6), 401-421.

Park, K. S., \& Oh, I. S. (2016). The Effect of Self-determination Motivation and Self-efficacy on Student Engagement: Focusing on the Mediating Effect of English Subjects Interest. Journal of Research in Curriculum \& Instruction, 20(4), 295-305. 
Park, S. J., \& Lee. J. W. (2019). Effect of 'Presence' Experience through e-sports Broadcasting on Pleasure, Immersion and Persistent Intention. Journal of Sport and Leisure Studies, 75, 253-265.

Pekrun, R. (2006). The control-value theory of achievement emotions: Assumptions, corollaries, and implications for educational research and practice. Educational Psychology Review, 18(4), 315-341.

Reeve, J., \& Jang, H. (2006). What teachers say and do to support students' autonomy during a learning activity. Journal of educational psychology, 98(1), 209-218.

Reeve, J., Jang, H., Carrell, D., Jeon, S., \& Barch, J. (2004). Enhancing high school students' engagement by increasing their teachers' autonomy support. Motivation and Emotion, 28, 147-169

Rotter, J. B. (1960). Some implications of a social learning theory for the prediction of goal directed behavior from testing procedures. Psychological Review, 67(5), 301-316.

Ryan, R. M., \& Deci, E. L. (2000). Intrinsic and extrinsic motivations: Classic definitions and new directions. Contemporary Educational Psychology, 25(1), 54-67.

Ryan, R. M., \& Deci, E. L. (2009). Promoting self-determined school engagement: Motivation, learning, and well-being. In K. R. Wenzel \& A. Wigfield (Eds.), Educational psychology handbook series. Handbook of motivation at school (p. 171 - 195).

Scanlan, T. K., \& Lewthwaite, R. (1986). Social psychological aspects of competition for male youth sport participants: IV. Predictors of enjoyment. Journal of sport psychology, $8(1), 25-35$.

Scanlan, T. K., \& Simons, J. P. (1992). The construct of sport enjoyment. In: Motivation in Sport and Exercise, G.C. Roberts (Ed.). Champaign, IL: Human Kinetics, pp. 199-215.

Scanlan, T. K., Carpenter, P. J., Simons, J. P., Schmidt, G. W., \& Keeler, B. (1993). An introduction to the sport commitment model. Journal of sport and exercise psychology, 15(1), 1-15.

Schilling, J. C. (2009). A Quantitative and Qualitative Investigation of Variability and Contextual Sources Related to the Academic Engagement of Minority and Economically Disadvantaged Adolescents. ProQuest LLC. 789 East Eisenhower Parkway, PO Box 1346, Ann Arbor, MI
48106.

Schukajlow, S., Leiss, D., Pekrun, R., Blum, W., Müller, M., \& Messner, R. (2012). Teaching methods for modelling problems and students' task-specific enjoyment, value, interest and self-efficacy expectations. Educational Studies in Mathematics, 79(2), 215-237.

Seligman, M. E., \& Csikszentmihalyi, M. (2014). Positive psychology: An introduction. In Flow and the foundations of positive psychology (pp. 279-298). Springer, Dordrecht.

Shen, B., Li, W., Sun, H., \& Rukavina, P. B. (2010). The influence of inadequate teacher-to-students social support on amotivation of physical education students. Journal of Teaching in Physical Education, 29, 417-432.

Shin, J. H., Jin, S. J. (2013). The Effects of the Life Goal Types on Academic Self-concept, Academic Effort, Test-Anxiety: The Moderating Effects of Academic Achievement Levels. The Korean Journal of Educational Psychology, 27(1), 161-180.

Soenens, B., \& Vansteenkiste, M. (2005). Antecedents and outcomes of self-determination in 3 life domains: The role of parents' and teachers' autonomy support. Journal of youth and adolescence, 34(6), 589-604.

Soenens, B., Vansteenkiste, M., Lens, W., Luyckx, K., Goossens, L., Beyers, W., \& Ryan, R. M. (2007). Conceptualizing parental autonomy support: Adolescent perceptions of promotion of independence versus promotion of volitional functioning. Developmental Psychology, 43(3), 633-646.

Song, C. H. (2003). The Influence of Teacher's Characteristics on The Children's Satisfaction of Class in Physical Education. Journal of Korean Society for the Study of Physical Education, 8(3), 45-57.

Standage, M., Duda, J. L., \& Ntoumanis, N. (2006). Students' motivational processes and their relationship to teacher rating in school physical education: $\mathrm{A}$ self $\mathrm{f}_{7}$ determination theory approach. Research Quarterly for Exercise and Sport, 77, $100-110$.

Taylor, I. M., \& Lonsdale, C. (2010). Cultural differences in the relationships among autonomy support, psychological need satisfaction, subjective vitality, and effort in British and Chinese physical education. Journal of Sport and Exercise Psychology, 32, 655-673. 
Van der Kaap-Deeder, J., Vansteenkiste, M., Soenens, B., \& Mabbe, E. (2017). Children's daily well-being: The role of mothers', teachers', and siblings' autonomy support and psychological control. Developmental psychology, 53(2), 237-251.

Vansteenkiste, M., Lens, W., \& Deci, E. L. (2006). Intrinsic versus extrinsic goal contents in self-determination theory: Another look at the quality of academic motivation. Educational psychologist, 41(1), 19-31.

Vargas-Tonsing, T. M., Warners, A. L., \& Feltz, D. L. (2003). The predictability of coaching efficacy on team efficacy and player efficacy in volleyball. Journal of Sport Behavior, 26(4), 396-407.

Wolters, C. A., \& Rosenthal, H. (2000). The relation between students' motivational beliefs and their use of motivational regulation strategies. International Journal of Educational Research, 33(7-8), 801-820.
Yang, J. S., \& Lee, S. H. (2011). Testing a Causal Model among Teacher and Parents' Autonomy Support, Basic Needs, Enjoyment, and Intention for Dance Classes. The Korean Journal of Arts Education, 9(1), 183-202.

You, J. W. (2011). Structural relationship among social factor, psychological mediators and motivational factor for enhancing learners' engagement. Unpublished doctoral dissertation, Ewha Womans University.

Yu, S. B., \& Sohn, W. S. (2013). Relationships of Perceived Maternal Emotional Expressiveness with Basic Psychological Needs and School Happiness for Korean Elementary Schoolers. The Korean Journal of School Psycholog, 10(1), 179-200.

Zimmerman, B. J., \& Martinez-Pons, M. (1990). Student differences in self-regulated learning: Relating grade, sex, and giftedness to self-efficacy and strategy use. Journal of Educational Psychology, 82(1), 51-59. 


\title{
체육수업 참여 중학생이 지각한 부모와 교사의 자율성지지, 즐거움, 자기효능감, 학업노력, 그리고 수업몰입의 관계
}

\author{
최헌혁 ${ }^{1}$, 조승관 ${ }^{2}$ \\ 1강원대학교 조교수 \\ ${ }^{2}$ 텍사스 A\&M 국제대학교 조교수
}

[목적] 본 연구는 체육수업 참여 중학생이 지각한 부모의 자율성지지와 교사의 자율성지지, 즐거움, 자기효 능감, 학업노력 그리고 수업몰입의 관계를 분석하고, 아울러 즐거움, 자기효능감, 그리고 학업노력이 부모의 자율성지지와 수업몰입의 관계뿐만 아니라 교사의 자율성지지와 수업몰입의 관계에서 어떠한 매개효과가 있 는지를 검증하는 것이다. [방법] 중학생 323명을 대상으로 부모와 교사의 자율성지지, 즐거움, 자기효능감, 학업노력, 그리고 수업몰입 질문지를 측정하였다. 수집된 자료는 SPSS 24.0 프로그램을 활용하여 신뢰도 분 석, 기술통계 분석과 상관분석을 실시하였다. 또한 Amos 22.0 프로그램을 활용하여 확인적 요인분석, 집중타 당도 분석, 판별타당도, 구조모형 분석을 실시하였고, 부트스트랩(bootstrap) 방법을 활용하여 매개효과를 검 증하였다. [결과] 첫째, 부모의 자율성지지는 즐거움과 자기효능감에 정적인 영향을 미쳤다. 둘째, 교사의 자 율성지지는 즐거움, 자기효능감에 정적인 영향을 미쳤다. 셋째, 즐거움, 자기효능감은 학업노력에 정적인 영향 을 미쳤다. 넷째, 학업노력은 수업몰입에 정적인 영향을 미쳤다. 여섯째, 부모의 자율성지지와 수업몰입의 관 계에서 즐거움, 자기효능감, 학업노력은 부분매개효과가 나타났다. 마지막으로 교사의 자율성지지와 수업몰입 의 관계에서 즐거움, 자기효능감, 학업노력은 부분매개효과가 나타났다. [결론] 체육수업에서 학생의 수업몰 입에 대한 과정을 확인하는데 부모의 자율성지지와 교사의 자율성지지의 역할을 확인함으로써 교육적 관점에 서 실용적 지식을 제공하고 교육현장에서 활용할 가치가 있다는 측면에서 의미가 있다.

주요어: 부모의 자율성지지, 교사의 자율성지지, 즐거움, 자기효능감, 학업노력, 수업몰입 